\title{
SubJETIVIDADE MIDIÁTICA: TEMPO E MEMÓRIA NO DISCURSO DAS BIOGRAFIAS CONTEMPORÂNEAS ${ }^{1}$
}

Felipe Pena*

\section{RESUMO}

$\mathrm{O}$ artigo tem como objetivo uma análise teórica sobre as abordagens dos conceitos de tempo e de memória (propostos por Elias e Derrida) na constituição da subjetividade produzida a partir do discurso das biografias contemporâneas. Nossa hipótese é a de que, na atualidade, as biografias são construídas diariamente na mídia, produzindo celebridades instantâneas que influenciam no agenciamento de identidades. Partimos, então, das reflexões de Pierre Bourdieu, para quem tais identidades são inscritas artificialmente através do que ele chama de ilusão biográfica, ou seja, a ilusão que trata a história de uma vida como "o relato coerente de uma seqüência de acontecimentos com significado e direção".

Palavras-chave: subjetividade, identidades, mídia, Derrida, Elias

\section{AbSTRACT}

MEDIATICAL SUBJECTIVITY: TIME AND MEMORY IN THE CONTEMPORARY BIOGRAPHICAL DISCOURSE

The goal of this article is to propose an analysis regarding the concepts of time and memory (as mentioned by Elias and Derrida) in the constitution of subjectivity produced by contemporary biographical discourse. Our hypothesis is that biographies are constructed every day in the media, producing celebrities that influence in identity arrangement. We follow Pierre Bourdieu's conclusions, for which these identities are subscribed through what he calls Biographical Illusion, "the one that takes a life story as a sequence of facts with meaning and direction".

Keywords: subjectivity, identities, media, Derrida, Elias

* Professor Doutor do Programa de Mestrado e Doutorado em Comunicação da Universidade Federal Fluminense; Jornalista; Doutor em Literatura pela Pontifícia Universidade Católica do Rio de Janeiro; Editor-chefe da Revista Contracampo; Comentarista da TVE-Brasil. 
Lembro, logo existo. No ritmo alucinante da contemporaneidade, com mudanças aceleradas e dissolução de certezas e referenciais, recorrer à memória é mais do que uma compensação. É uma tentativa desesperada de encontrar alguma estabilidade diante da reordenação espacial e temporal do mundo. Lembrar é trazer de volta antigos modos de vida e experiências sociais. É tentar reviver momentos de coerência e estabilidade.

Para Jesus Martín-Barbero (2000), vivemos um "boom de memória”, causado pela crise na moderna experiência do tempo. Barbero identifica várias manifestações desse boom: crescimento e expansão dos museus, restauração dos velhos centros urbanos, auge do romance histórico, moda retrô na arquitetura e no vestuário, entusiasmo por comemorações, multiplicação de antiquários e um grande interesse pelas biografias e autobiografias.

O relato biográfico, na maioria das vezes, tenta ordenar os acontecimentos de uma vida de forma diacrônica, na ilusão de que eles formem uma narrativa autônoma e estável, ou seja, uma estória com princípio, meio e fim, formando um conjunto coerente. É o que Pierre Bordieu (1998) chama de ilusão biográfica, aquela que trata a história de uma vida como "o relato coerente de uma seqüência de acontecimentos com significado e direção" (Bourdieu, 1998: 185).

Para Bordieu, o biógrafo é cúmplice desta ilusão. Ele tenta satisfazer o leitor tradicional, que espera dele uma suposta verdade, uma suposta realidade. Mas o máximo que a biografia pode oferecer é uma reconstrução, um efeito de real. $\mathrm{O}$ biógrafo é o responsável pela criação artificial de sentido, já que tem interesse em aceitar a coerência da existência narrada, pois seu discurso baseia-se na preocupação de "tornar razoável, de extrair uma lógica ao mesmo tempo retrospectiva e prospectiva, uma consistência e uma constância, estabelecendo relações inteligíveis, como a do efeito à causa eficiente ou final" (Bourdieu, 1998: 185). Ao organizar a vida como uma estória linear, o biógrafo fornece uma razão de ser ao seu objeto e tranqüiliza o seu leitor, que se identifica no passeio pela "estrada percorrida".

Associar a vida a um caminho ou estrada facilita a compreensão, facilita a narração, facilita a venda. $\mathrm{O}$ sucesso das biografias no mercado editorial está certamente relacionado à opção da maioria dos autores de reconstruir o passado atribuindo significado aos fatos dispersos de uma vida, alocando-os em ordem cronológica. Estamos sendo seduzidos pela memória, diria Andréas Huyssen (2000). Mas a sedução vive de um modelo epistemológico anacrônico e não contempla as transformações na experiência espacial e temporal.

Para começar, não há como pensar a memória sem pensar o esquecimento. Os termos não são antagônicos e não podem ser pensados em um defasado mode- 
lo dicotômico. Eles convivem e se relacionam em complexas teias de conexão e interfaces. No mundo dos megabytes, nunca foi tão fácil armazenar memória, mas a amnésia nunca esteve tão presente. $\mathrm{O}$ excesso de informação convive com o esquecimento imediato. A cultura midiatizada produz objetos descartáveis que alimentam a própria amnésia: "a velocidade sempre crescente das inovações técnicas científicas e culturais gera quantidades cada vez maiores de produtos que já nascem obsoletos" (Huyssen, 2000: 27). Mas, como alerta Huyssen, este não é um movimento unilateral, ou seja, não se pode argumentar que a "comercialização de memórias gere apenas esquecimento" (Huyssen, 2000: 22), como sugere a interpretação apocalíptica de Adorno (1988). É preciso refletir sobre a amnésia pela ótica da lembrança. E vice-versa.

No interior desse movimento duplo e paradoxal, manifesta-se o próprio medo da perda da memória, outra razão para a sua supervalorização na atualidade, embora não se possa dizer que este é um medo novo. A cada nova técnica de armazenamento descoberta há resistências. Foi assim com o alfabeto grego, com a imprensa de Gutemberg, o satélite e o computador, etc. Para Lúcia Santaella (2000), o aparecimento de cada novo meio de produção e contenção de linguagem e de memória representa o deslocamento de alguma habilidade humana do nível individual para o coletivo e, "nesse deslocamento, o homem transitoriamente perde uma parte de si, a imagem que tem de si e do mundo. Nessa imagem estão consubstanciados os valores humanos, que são tão relativos quanto a própria imagem. Se a imagem se fragmenta, os valores escorregam entre as fendas" (Santaella, 2000: 87).

O "consumidor" da memória quer fechar essas fendas, quer comprar a estabilidade: "as narrativas biográficas e autobiográficas oferecem um enquadramento retrospectivo e prospectivo ao ordenarem a vida articulando memória e aspirações dos indivíduos, suas motivações e o significado de suas açōes numa conjuntura própria de vida”, concluem Rondelli e Herschmann (2000: 203). Além disso, a memória na mídia é espetacularizada, carregada de imagens pré-concebidas, facilitando ainda mais a sedução.

Em um livro publicado há quase dez anos (Pena, 1998), relato esse tipo de sedução. Ao analisar a possibilidade de uma utopia contemporânea, diferenciando-a das utopias socialistas da década de 60, identifico minhas próprias construções midiatizadas produzidas a partir da leitura de biografias.

Como todo adolescente, sempre estive ao lado dos oprimidos. Era ávido consumidor de livros marxistas. Li Engels, Lênin, Kautsky, Plekhânov e Florestan Fernandes antes de completar 14 anos. Não que eu entendesse as explanações 
teóricas, mas era levado a elas por outras leituras, e estas sim me emocionavam. Os livros do Gabeira, do Sirkis, do Marcelo Rubens Paiva, entre outros, falavam de dramas pessoais em meio ao drama maior da luta contra a repressão (Pena, 1998: 20).

As leituras dessas estórias me faziam ter saudade de um tempo que eu não vivi. Elas me faziam querer participar da passeata dos cem mil, freqüentar o opinião, acompanhar Lamarca pelo sertão da Bahia e lutar com Marighela. Elas me faziam querer voltar para onde eu nunca tinha ido, daí o título $A$ volta dos que não foram. Mas o que pude perceber é que eu tinha uma imagem midiatizada do passado, produzida pela espetacularização da narrativa que consumi, já que, como diria Jameson (1996), eu buscava a história através de "minhas próprias imagens pop e dos simulacros daquela história” (Jameson, 1996: 52). Só que ela continuaria, para sempre, fora do meu alcance. Entretanto, não há como negar que a consciência de meus estereótipos não significa livrar-me deles, apenas me permite uma atitude crítica sobre meu próprio trabalho e o respeito à diversidade e à complexidade, que devem ser o tapete de minhas reflexões.

A atitude reflexiva sobre seus próprios estereótipos, simulacros e imagens pop é, então, uma necessidade para o biógrafo. Um trabalho que deve anteceder qualquer tentativa de construção de uma biografia. Como alerta Diana Damasceno (1999), "escrever biografias em nossos dias requer consciência aguda do processo de re-interpretar o passado como forma particular de construção, sujeita a variados desdobramentos, levando em conta que vidas podem ser entendidas como sistemas complexos" (Damasceno, 1999: 97). Entretanto, quem acaba se ocupando das reflexões são os teóricos, não os biógrafos. Estes têm a atitude profissional do abridor de latas, que penetra nos arquivos e busca as salsichas da realidade. Quando, repito, o máximo que eles podem oferecer é um efeito de real.

A re-interpretação do passado, sugerida por Damasceno, passa impreterivelmente pela rediscussão dos conceitos de tempo e memória. Para Derrida (1988), essa reconceitualização significa abdicar da noção de linearidade temporal e substituí-la por simultaneidade. No momento em que lembramos de algo, o que era passado torna-se narrativa e articula-se no presente, sendo portanto simultâneo a este presente. E o que seria futuro é apenas uma especulação, podendo ser articulado apenas no discurso, o que também o tornará presente.

Nesse sentido, a memória só é memória no esquecimento ou no segredo, pois quando acionada também se torna discurso. Pelo mesmo raciocínio, a memória não substitui o passado, apenas mostra que ele falta (Derrida, 1988). Mas o biógrafo (ou o historiador) tradicional acha que vai preencher as lacunas. Ledo 
engano. A estória de qualquer coisa é apenas o que podemos saber sobre esta coisa, jamais a totalidade. A lacuna é onipresente. $\mathrm{O}$ passado não está pronto. Ele ainda está por fazer e se articula no presente, ou melhor, na presença, onde elaboramos a memória e a transformamos em discurso. Mais uma vez trabalhando no paradoxo, Derrida articula o conceito de presença com o de ausência, valorizando a escrita, que, quando legível e iterável, produzirá uma marca para ser repetida em qualquer contexto, sobrevivendo ao sujeito e não precisando mais de sua presença. A escrita funda outra presença e garante a repetição. Na interpretação de Adriana Amaral (2000), a ausência em Derrida deixa de ser ausência justamente se pensada como a fundação de um outro tipo de presença.

Essa capacidade de atravessar contextos da escritura é que a faz presença feita de ausência, onde a ausência na verdade se funde na presença em um presente que se faz a cada novo instante, a cada novo contexto. [...] A marca (da escrita) garantirá a repetição em qualquer contexto, visto que nenhum contexto se fecha mais sobre si mesmo e tampouco possui um centro absoluto. Ora, esse atravessar de contextos é próprio da escrita se comparada com a fala que deixa inclusive de ser uma oposição quando se pensa que ela também é feita de referência e não da coisa em si (Amaral, 2000: 34).

Para Derrida, então, há duas memórias: a interior, relativa ao ser, e a totalizadora, relativa à escritura. "A diferença é que a memória do ser se extingue e é absorvida por outras memórias. [...] O ser se apaga e a escrita se inscreve" (Amaral, 2000: 37). Entretanto, o modelo de Derrida também pode ser criticado por essa dicotomia. A escritura não é totalizadora. Muito menos a narrativa. Pode-se argumentar que a forma privilegiada pelos historiadores é a narrativa, mas ela não é a única. É possível um experimento historiográfico que não se encaixe no modelo narrativo. Um experimento que lide com pequenas ficções e pequenas generalizaçôes, juntando scripts, articulando fragmentos e colocando pequenos quadros lado a lado. Um experimento como o que faz Hans Gumbrecht (1999), por exemplo, no livro Em 1926: vivendo no limite do tempo.

Partindo da ausência para fundar outra presença, a escrita leva o significado sempre para a posteridade. Nesse sentido, rompe com a idéia de linearidade temporal, já que o instante original das formulações jamais seria atingido, pois ele não estaria no passado, mas na sua re-interpretação no presente. Prevalece a idéia de simultaneidade. Prevalece a presentificação do tempo.

O movimento é reciclável. O ser se apaga, mas, em seguida, inscreve-se de novo. A origem é sempre re-inaugurada, até porque cada momento é único e não 
pode ser resgatado em seu exato teor. E, se a memória não resgata a exatidão, o momento já será outro no instante do resgate, que passa a ser a parte mais importante desse processo. Nenhum sentido pode ser considerado como previamente constituído. Nada está pronto, tudo está sendo feito. O que nos interessa é o percurso, não a origem ou a meta.

Entretanto, estar preso ao presente reforça o medo e a angústia. "O futuro é improvável demais e o presente complexo demais para nos darem acolhida. Exilado de si mesmo, o homem busca asilo no passado" (Santaella, 2000: 92). Um asilo nos revivals, nas retrospectivas, na nostalgia. Para Jean Baudrillard (2001), uma obsessão em reviver: "é a memorização fanática, uma fascinação pelas comemoraçõoes, a listagem de lugares da memória, a exaltação da herança” (Baudrillard, 2001: 46).

A obsessão pelo passado, segundo Baudrillard, leva ao desaparecimento da própria memória, que, por sua vez, leva ao desaparecimento do real, reduzindo-o a um simulacro: "isso resulta em transformar o próprio passado num clone e congelá-lo numa imitação falsa que jamais lhe fará justiça” (Baudrillard, 2001: 46). Mais uma vez, cabe uma crítica ao modelo dicotômico, também usado por Baudrillard. Ao falar em uma imitação falsa, ele pressupõe que exista um original. Mas será possível, diante das múltiplas e complexas teias de significação da atualidade, fazer essa oposição dicotômica entre o real e o simulacro? Acredito que não. Mas, para Baudrillard, a impossibilidade de ver além do presente nos condena a viver uma realidade virtual. Sua crítica abrange o que ele chama de "musealização" da memória que, longe de preservar o passado, apenas o esteriliza e congela: "em vez de primeiro existirem, as obras de arte hoje vão diretamente para o museu. Em vez de nascerem e morrerem, os seres já nascem como fósseis virtuais" (Baudrillard, 2001: 46). Ou seja, nascem no presente para serem alocadas em um passado presentificado, simultâneo.

A idéia de simultaneidade temporal também encontra eco em Norbert Elias (1998): "Em sua qualidade de simbolizações de períodos vividos, essas três expressōes (passado, presente e futuro) representam não apenas uma sucessão, como 'ano' ou o par 'causa-efeito', mas também a presença simultânea dessas três dimensões do tempo na experiência humana" (Elias, 1998: 63).

Para Elias, vivemos a ilusão do tempo como objeto mensurável. Uma hora ou um ano não têm o mesmo sentido - como já ensinara Einstein - para indivíduos diferentes e devem ser avaliados relativamente. Para um presidiário que espera, no corredor da morte, o momento de ser executado, a hora não passará na mesma velocidade que para um homem que espera a noiva no aeroporto. Tentamos medir o que não pode ser percebido pelos sentidos. E fazemos isso usando locuçôes que sugerem que o tempo é um objeto físico: "o vocabulário de que 
dispomos oferece ao sujeito expressões como determinar ou medir o tempo. Esses hábitos lingüísticos contribuem para distorcer a reflexão” (Elias, 1998: 37). A língua, socialmente padronizada, recorre ao que ele chama de "substantivos reificadores", acompanhados de verbos que, metaforicamente, reforçam a idéia do tempo apenas como dimensão física. "Pensemos em frases como 'o vento sopra' ou 'o rio corre': afinal, seria o vento outra coisa senão a própria ação de soprar, ou rio outra coisa senão a água correndo?” (Elias, 1998: 37).

O tempo é regulado socialmente. Não comemos quando sentimos fome, mas na hora do almoço ou do jantar. Também não vamos dormir quando estamos cansados, mas no final da noite. Nossos ritmos biológicos são ordenados em função da organização social, que obriga os homens a se disciplinarem. E, a longo prazo, o calendário regula nossas relaçôes sociais, padronizadas em efemérides e datas comemorativas. Como o tempo não é visível, tangível ou mensurável, Elias sugere que a regulação social privilegia a sincronia e não a diacronia, encurralando o indivíduo na infinita repetição do presente.

Assim, encurralado em um presente de larga complexidade, o indivíduo atomiza-se diante da dificuldade de conceber uma experiência temporal coerente. Para Jameson (1996), o resultado é uma fragmentação de suas referências, dominadas pela (i)lógica espacial:

Se, de fato, o sujeito perdeu sua capacidade de entender de forma ativa suas pretensões e retençôes em um complexo temporal e organizar seu passado e seu futuro como uma experiência coerente, fica difícil perceber como a produção cultural de tal sujeito poderia resultar em outra coisa que não um amontoado de fragmentos e uma prática da heterogeneidade a esmo (Jameson, 1996: 52).

Jameson também trabalha na dicotomia. Ele usa o termo aleatório de forma negativa. Sua tendência é procurar uma nova explicação totalizadora, propondo um mapeamento cognitivo em que o intelectual teria como missão situar o indivíduo no mundo através do fornecimento de um mapa crítico.

Preso no agora, este indivíduo vive uma situação de inércia, exilado na transitoriedade que não leva a lugar algum. Ele sobe e desce as escadas de edifícios memorialísticos, cujos degraus mudam a cada passada. Dirige um táxi de lembranças e as compartilha com os diferentes passageiros que recolhe em cada esquina. Mas continua só. Pisa na embreagem, passa a quinta marcha e acelera pelos círculos da metrópole. Vaga pelas ruas, mas não chega a lugar nenhum, porque nunca partiu.

A pior solidão é a solidão na multidão, característica do espaço urbano. $\mathrm{O}$ sujeito está exilado na própria (a)temporalidade, estático diante de um universo 
desenraizado, sem referências. Mesmo assim, a paralisia lhe parece normal, não causa surpresa. É a inércia diante da inércia. Os espaços são transitórios. Seu lar é um hotel. A superficialidade é seu enredo.

Mas ele continua a viagem. Apesar de o espaço ser móvel, ele não se livra de estar encurralado. Preso na falta de objetivos e referenciais, segue em seu exílio. Diante da incapacidade de organizar diacronicamente o passado, ele se exaure na contemplação vazia, embora hipnótica, do presente. A falta desta articulação entre passado e presente (sem projeto de futuro) e a visão do tempo como momentos isolados desencadeiam a esquizofrenia como descrita por Frederic Jameson (1996), retomando a noção de Lacan sobre a quebra na cadeia de significantes. Se não é possível organizar a sentença, também não será possível a experiência biográfica, perdida na superficialidade momentânea. E a desconstrução da oposição semiótica entre significante e significado será apenas um dos quatro modelos fundamentais de profundidade que, segundo Jameson, têm sido repudiados pela teoria contemporânea. Os outros três são:

1) o dialético, da essência e da aparência, bem como toda a gama de conceitos correlatos de ideologia ou de falsa consciência; 2) o modelo freudiano do latente e do manifesto, ou da repressão; 3) o modelo existencialista da autenticidade e da inautenticidade, cuja temática heróica está ligada àquela outra grande oposição entre alienação e desalienação (Jameson, 1996: 40).

$\mathrm{Na}$ verdade, a ausência de todos os modelos descritos acima interage na maneira esquizofrênica de perceber o mundo. A identidade está irreversivelmente comprometida na medida em que o sujeito é incapaz de estabelecer ligaçôes entre os diversos momentos de sua história e também de estabelecer modelos de reconhecimento. A personalidade é dividida mediante o processo de fragmentação, com o conseqüiente esmaecimento do afeto. Os sentimentos se diluem na quebra da cadeia de significantes e estão presos a uma superficialidade em que o referente histórico é inacessível. O que seria a realidade histórica se apresentar apenas como imagens nebulosas que não se referem a um passado, mas às nossas idéias e imagens espetacularizadas deste passado, novamente na interpretação de Jameson:

Se sobrou algum tipo de realismo aqui, é o "realismo" derivado do choque da percepção desse confinamento e da consciência gradual de que estamos condenados a buscar a história através de nossas próprias imagens pop e dos simulacros daquela história que continua para sempre fora do nosso alcance (Jameson, 1996: 52). 
Mas, se o passado está fora de alcance, não pode ser totalizado, o que ficou foi a imagem, a distância, a névoa. E a reação perante esta ausência também é de inércia. A banalidade é patente. Até que, em certo instante da narrativa de suas lembranças, já presentificadas pela articulação do discurso, o indivíduo pisa no terreno escorregadio da nostalgia. Quer musealizar a memória e erguer estátuas e monumentos que possam pavimentar a estrada para um retorno. Só que o caminho de volta está fechado para sempre. Um sentimento de perda registrado pela percepção da grande transformação que é a espacialização do temporal "nos leva à nostalgia da nostalgia, das grandes questões do télos e da origem, do tempo profundo e do inconsciente freudiano e também da dialética..." (Jameson, 1996: 173).

Para Neal Gabler, "vivemos no mundo da pós-realidade” (Gabler, 1999: 17). $\mathrm{Na}$ encenação do real, o veículo vida gera novos episódios diariamente, fazendo com que as aplicações que a mídia descobre para esses episódios ultrapassem a própria realidade. Revistas de fofocas, periódicos sobre famosos e programas de TV como "Vídeo Show" e "TV Fama" vivem da encenação e a repercutem infinitamente em novas encenações. A mídia produz celebridades para poder realimentarse delas a cada instante em um movimento cíclico e ininterrupto. Até os telejornais são pautados pelo biográfico e acabam competindo com os filmes, novelas e outras formas de entretenimento. São notícias do parque encantado, como se os redatores-chefes fossem Lewis Carroll ou Monteiro Lobato. E mesmo quando há assassinatos ou graves acidentes o assunto principal é sempre a celebridade ou o candidato ao estrelato, que, inclusive, pode ser o próprio assassino ou um outro delinqüente qualquer.

O julgamento do ex-astro do futebol americano O. J. Simpson, a vida e a morte da princesa Diana, a interminável novela fornecida pelas peripécias de Elizabeth Taylor ou pela apresentadora de televisão Oprah Winfrey, o assassinato da donade-casa de Long Island Mary Jo Buttafuoco pela jovem amante do marido, a bomba colocada pelo dissidente de direita numa repartição federal em Oklahoma City, as constantes alegações de aventuras extraconjugais do presidente Bill Clinton, para lembrar apenas um punhado, entre literalmente milhares de outros episódios gerados pela vida, são esses os novos sucessos de bilheteria que ocupam as mídias tradicionais e dominam as conversas nacionais por semanas, às vezes meses ou até anos a fio, ao passo que o entretenimento comum desaparece rapidamente de cena (Gabler, 1999: 13).

A espetacularização da vida toma o lugar das tradicionais formas de entretenimento. Cada momento da biografia de um indivíduo é superdimensionado, 
transformado em capítulo e consumido como um filme. Mas a valorização do biográfico é diretamente proporcional à capacidade desse indivíduo de roubar a cena, ou seja, de tornar-se uma celebridade. Aliás, as celebridades tornaram-se o pólo de identificação do consumidor-ator-espectador do espetáculo contemporâneo. São elas que catalisam a atenção e preenchem o imaginário coletivo. O que é muito diferente da identificação com os heróis, uma tradição da cultura ocidental, como alerta Ronaldo Helal (2001), recorrendo às interpretaçôes de Joseph Campbell e Edgar Morin para diferenciar herói de celebridade: "o primeiro vive para 'redimir a sociedade de seus pecados', vive para os outros, enquanto o segundo vive somente para si" (Helal, 2001: 18).

O herói acredita que tem uma missão a cumprir. Ele deve domar o cotidiano e viver na esfera do extraordinário. Deve entregar-se ao seu propósito maior e ao seu destino glorificado, que será construído única e exclusivamente por ele mesmo, já que ele é senhor de seus atos, pois tem "um senso interior de certeza de que com circunspeção, habilidade e compulsão é possível superar os maiores perigos e infortúnios, e de que é capaz de fazer seu próprio destino" (Featherstone, 1997: 87).

O reconhecimento do povo, que leva o herói à glória, também fixa sua imagem mitificadora, diferenciando-o dos meros mortais. Talvez por isso tantos políticos, artistas e outros habitantes (ou não) do espaço público contemporâneo tentem construir imagens de heróis em torno de suas vidas. Mas, se não é possível estar em um enredo de Homero, talvez seja mais simples escrever a própria estória, produzindo uma autobiografia. E é claro que os conceitos relacionados ao herói estarão presentes no discurso; afinal, se o indivíduo se dispôs a escrever a própria estória, sua existência só pode ter sido excepcional. Lá estarão a areté, a timé, a missão a cumprir, o controle do destino, o gesto do conquistador e todas as outras características extraordinárias de sua personalidade. Em sua autobiografia, por exemplo, Carlos Lacerda $(2001)^{2}$ quer mostrar sua vida heróica, ilustrada pela luta corajosa e pelo senso interior de que tem a missão de reconstruir o Brasil. Ele tenta fazer isso intercalando a narrativa com fatos da vida cotidiana, mas não consegue disfarçar seus claros propósitos. Para Lacerda, seu destino é óbvio: ser presidente da república. E não poderia ser menos, já que carrega a honra e a excelência dos heróis. Se Aquiles é o melhor dos aqueus, ele é o melhor dos brasileiros:

O sentido de que se tem uma missão a cumprir, seja de criar os filhos ou de reformar uma nação, de fazer o que se sabe e o que se pode - não importa o vulto da tarefa e sim sua significação -, a idéia de que se deve procurar fazer bem feito tudo o que se tem a fazer, por mais simples ou arriscado que seja, faz 
parte desse sentido de missão. Também dele é estar disponível para cumpri-la. E ser acessível, [...] de modo a ser mobilizado, a qualquer momento, para a missão a que se está, por assim dizer, destinado (Lacerda, 2001: 81).

O sentido de missão a cumprir descrito nas autobiografias pode, muitas vezes, ser identificado nos próprios títulos. Carlos Lacerda batizou a sua de Rosas e pedras de meu caminho. Samuel Wainer (1987) escreveu Minha razão de viver. Adolf Hitler pariu Minha luta ([1925-1926] 2005). Todos tentaram justificar suas "açōes heróicas", independentemente das implicaçōes ideológicas. O senso de controle do próprio destino a partir da crença em um propósito superior fez com que cada um acreditasse ser um indivíduo especial, único, o mais insubstituível dos seres. Mas eles não foram os primeiros. No século XVIII, Jean Jacques Rousseau ([1770] 1948) já deixara patente essa crença na introdução de suas confissões: “a natureza perdeu a fôrma em que me moldou” (Rousseau, [1770] 1948: 9).

Entretanto, o espaço público (e midiático) contemporâneo é ocupado pelas celebridades, que são o "eu" espetacularizado, e não pelos candidatos a heróis. Elas acabam sobrepondo-se às próprias estrelas produzidas pela mídia no âmbito das tradicionais formas de entretenimento, como o teatro, o cinema e a TV. Quando os atores da TV Globo dão entrevistas sobre os participantes do Big Brother Brasil, eles estão entrando nessa lógica. É a estrela opinando sobre o anônimo que virou uma celebridade instantânea. O movimento inverso do star system. Até os próprios autores de novelas, acostumados a produzir estrelas, percebem esse movimento. Para Silvio de Abreu, por exemplo, o fenômeno é bem anterior aos reality shows: "o melhor exemplo de que vivemos na era das celebridades instantâneas é a Adriane Galisteu. Quando a casa dela é assaltada, primeiro ela chama a revista Caras, depois chama a polícia”3.

A atitude de Adriane não é gratuita. A exposição da intimidade é uma das principais estratégias de sobrevivência das celebridades. Despertar com a buzina do programa do Gugu, enquanto o Brasil conhece seu quarto e sua camisola (ou a falta dela), mantém a celebridade no espelho. Mais do que se identificar, o espectador se vê na figura da estrela instantânea. Aquela poderia ser a cama dele, tamanha é a intimidade que os une. A mídia cria um sentido de auto-semelhança.

No artigo "Invasão de privacidade? Reflexões sobre a exposição da intimidade na mídia”, Maria Celeste Mira (1998) analisa a transformação histórica da noção de intimidade para defender a tese de que o conceito de intimidade das classes populares não é o mesmo das classes de maior poder econômico. Baseando suas reflexões em Jürgen Habermas e Norbert Elias, Mira volta à Idade Média para mostrar que os cômodos das casas e palácios não eram especializados como 
hoje, o que só vai acontecer com a ascensão da burguesia: "como se sabe, a intimidade é uma criação burguesa que, como esclareceu Habermas, vai dividir o espaço social entre a esfera pública e a esfera privada, no interior da qual se situará outra ainda mais recolhida, a esfera íntima” (Mira, 1998: 98).

No Antigo Regime, o mesmo aposento poderia servir para comer, dormir ou até receber visitas. $\mathrm{Na}$ ausência de corredores, passava-se pelo interior dos cômodos para circular pelas casas. Na interpretação de Mira, "não estava aí presente a idéia de que determinadas atividades da vida diária pertenciam a uma esfera íntima” (Mira, 1998: 99). O próprio despertar do Rei era acompanhado por integrantes da corte, que o auxiliavam em sua toalete matinal. $\mathrm{O}$ impulso de esconder a nudez ou os cuidados corporais não era tão difundido. Os banhos eram coletivos e não havia roupas especiais para dormir. Era comum pessoas de sexos e idades diferentes dormirem nuas no mesmo quarto.

Para Norbert Elias, a partir do século XVII, começa a haver uma preocupação maior com o pudor, primeiro nas classes mais altas e depois nas mais baixas, que mantêm por mais tempo os velhos costumes. Mira defende a idéia de que essa demora se deve à pouca significação que a casa popular tem para seus moradores, já que seu espaço reflete as difíceis condiçôes de vida dessa classe. A própria relação com a família é esvaziada de sentimentos, limitando-se a uma estratégia de sobrevivência. O verdadeiro "lugar de trocas afetivas", como observa Elias, é no interior do que ele chama de "comunidade familiar estendida" (Mira, 1998: 100), ou seja, um círculo social que incluía comadres, primos, afilhados e vizinhos. Como as carências sociais eram grandes, o isolamento representava um grande perigo para as classes baixas. Daí a sociabilidade popular funcionar como um cinturão de proteção contra o frio, a fome e outras mazelas.

Mas esse raciocínio é inverso na burguesia, que passa a enaltecer o isolamento e os valores ligados à família, numa tentativa de se diferenciar das classes populares. A vida profissional deve ser separada da vida familiar. A casa, como diz Benjamim (1985), é a expressão da personalidade do burguês. E ela vai ser individualizada, com cômodos específicos e isolados, valorizando a intimidade. $\mathrm{O}$ amor romântico, difundido pelo romance burguês, e a moral puritana também serão determinantes para a valorização da esfera íntima no imaginário da burguesia. A vida sexual pertence à intimidade.

Toda essa reconstrução histórica serve para Mira (1998) justificar a maior penetração que as revistas de fofocas e os programas invasores de privacidade na TV têm nas classes populares. Segundo a pesquisadora, as condiçôes de vida das classes populares continuam precárias e elas ainda recorrem aos círculos de sociabilidade como estratégia de sobrevivência, identificando seus pares em locais de 
encontro como bares, templos ou clubes e socializando o acesso ao espaço da casa, sem se importar com a diluição da privacidade.

Da mesma forma, o modo de apropriação do conteúdo midiático também é socializado. A audiência da TV é coletiva. O aparelho é colocado na sala, de frente para a porta, e os vizinhos têm livre aceso ao sofá. "Há boas razões para acreditar que a propagação do modo de vida burguês não destruiu totalmente o que as classes populares cultivaram durante séculos em todo o ocidente" (Mira, 1998: 109). A partir desse raciocínio, Mira conclui que, lendo sobre a vida das celebridades, as pessoas tornam-se cada vez mais íntimas delas, recriando o contexto do bairro ou da pequena comunidade, onde a vida privada do indivíduo interessa a todos e a intimidade é socializada. "Através da mídia e das novas tecnologias podem ser criados novos sentidos de comunidade: uma comunidade 'sem lugar' ou, como propõe Meyerowitz, uma comunidade que independe do local” (Mira, 1998: 113).

Mas, se as classes altas valorizam mais a privacidade, inclusive no ato de assistir TV, já que os aparelhos ficam nos quartos ou em ambientes específicos, não é verdade que elas sejam menos seduzidas pela exposição da intimidade das celebridades. É possível que o raciocínio de Mira refira-se mais especificamente às revistas de fofoca e a programas de TV como Ratinho ou Gugu, pois seu texto é anterior à explosão dos reality shows no Brasil. Mas a audiência do Big Brother Brasil I demonstra que as classes mais altas também gostam do buraco da fechadura, o que talvez se explique pela identificação dos personagens com a classe média e pelo desejo da platéia de também ser ator do espetáculo.

A vida é midiática e deve ser vivida como um espetáculo em que todo dia há um novo capítulo, e onde, invariavelmente, a intimidade está presente. "Sei mais sobre a vida íntima de Lady Di que sobre minhas amigas” (Mira, 1998: 97).

Se, no passado, era preciso ler a biografia de uma estrela para conhecer passagens de sua intimidade que ela julgasse conveniente divulgar, hoje a biografia é escrita diariamente na mídia. O espaço dos heróis (mesmo os pré-fabricados) foi ocupado pelas celebridades e a superexposição substituiu a virtude (areté) como valor supremo. Estamos na era das subjetividades midiáticas.

\section{REFERÊNCIAS BIBLIOGRÁFICAS}

Adorno, T. (1988). Dialética do esclarecimento. Rio de Janeiro: Zahar.

Adorno, T. \& Horkheimer, M. (1986). Dialética do esclarecimento. São Paulo: Zahar.

Amaral, A. (2000). Sobre a memória em Jacques Derrida. Em Nascimento, E. \& Glenadel, P. Em torno de Jacques Derrida (pp. 23-38). Rio de Janeiro: Sette Letras. 
Baudrillard, J. (2001). A ilusão vital. Rio de Janeiro: Civilização Brasileira.

Benjamin, W. (1985). A imagem de Proust. Em Magia e técnica, arte e política. Obras Escolhidas (pp. 71-94). São Paulo: Brasiliense.

Bourdieu, P. (1998). A ilusão biográfica. Em Ferreira, M. \& Amado, J. Usos e abusos da história oral (pp. 183-197). Rio de Janeiro: Ed. FGV.

Damasceno, D. (1999). Entre múltiplos eus: os espaços da complexidade. Tese de Doutorado, Departamento de Letras, Pontifícia Universidade Católica do Rio de Janeiro.

Derrida, J. (1995). A escritura e a diferença. São Paulo: Perspectiva. - (1988). Mémoires pour Paul de Man. Paris: Galilée.

Elias, N. (1998). Sobre o tempo. Rio de Janeiro: Zahar.

Featherstone, M. (1997). O desmanche da cultura. São Paulo: Nobel.

Gabler, N. (1999). Vida, o filme. São Paulo: Cia das Letras.

Gumbrecht, H. U. (1999). Em 1926: vivendo no limite do tempo. Rio de Janeiro: Record.

Habermas, J. (1984). Mudança estrutural na esfera pública. Rio de Janeiro: Tempo Brasileiro.

Hall, S. (2001). A identidade cultural na pós-modernidade. Rio de Janeiro: DP\&A.

Helal, R. (2001). Cultura e idolatria: ilusão, consumo e fantasia. Rio de Janeiro: mimeo.

Hitler, A. (1925-1926). Minha luta. São Paulo: Centauro, 2005.

Huyssen, A. (1997). Memórias do modernismo. Rio de Janeiro: Ed. da UFRJ.

- (2000). Seduzidos pela memória. Rio de Janeiro: Aeroplano.

Jameson, F. (1996). Pós-modernismo - a lógica cultural do capitalismo tardio. São Paulo: Ática.

Lacerda, C. (2001). Rosas e pedras de meu caminho. Brasília: Ed. da UNB.

Martín-Barbero, J. (2000). Dislocaciones del tiempo y nuevas topografias de memoria. Rio de Janeiro: Artelatina.

Mira, M. C. (1998). Invasão de privacidade? Reflexôes sobre a exposição da intimidade na mídia. Lugar Comum, 5-6, 97-116.

Pena, F. (1998). A volta dos que não foram. Rio de Janeiro: Sette Letras.

(2004). Teoria da biografia sem fim. Rio de Janeiro: Mauad.

Rondelli, E. \& Herschmann, M. (2000). A mídia e a construção do biográfico. Revista Tempo Social, $\mathrm{n}^{\circ}$ 1, v. 12, 279-309.

Rousseau, J.-J. (1770). As confissões. Rio de Janeiro: José Olympio, 1948.

Santaella, L. (2000). Cultura das mídias. São Paulo: Experimento.

Wainer, S. (1987). Minha razão de viver. Rio de Janeiro: Record. 


\section{Notas}

1 Este artigo é uma adaptação da Tese de Doutorado do autor.

2 Publicada na década de 70 pela revista Manchete e reeditada pela editora da universidade de Brasília em 2001.

3 Entrevista a Gabriela Goulart. Caderno B, Jornal do Brasil, 12/01/2002.

Recebido em 30 de maio de 2007 Aceito para publicação em 9 de agosto de 2007 